\title{
Formulasi Strategi Menggunakan Bisnis Model Canvas
}

(Studi Kasus Pada Bisnis Distro di Jalan Padjajaran Bandung Jawa Barat)

\author{
Sugiyanto ${ }^{1)}$ Muhammad Aditya Pratama ${ }^{2)}$, dan Endang Wahyuningsih ${ }^{3)}$ \\ Program Studi Magister Manajemen Ikopin 1) dan 2) \\ Diploma Tiga Manajemen Bisnis ${ }^{3)}$ \\ Institut Manajemen Koperasi Indonesia \\ giyant2000@ikopin.ac.id
}

\begin{abstract}
Abstrak
Industri fashion berperan penting dalam pertumbuhan industri kreatif nasional yang banyak menyerap tenaga kerja. Pelaku bisnis yang dipilih sebagai sampel penelitian ini sebanyak 4 distribution store (Distro), berlokasi di Jl Padjajaran, Bandung. Persaingan yang semakin ketat menjadi masalah utama, ditandai dengan semakin menurunnya pendapatan dan profitabilitas. Tujuan penelitian ini untuk memformulasikan strategi bisnis distro menggunakan analisis SWOT dan BMC. Pendekatan penelitian deskriptif kualitatif dan kuantitatif digunakan dalam penelitian ini. Penelitian kualitatif untuk mengidentifikasi faktor-faktor kekuatan, kelemahan, kesempatan dan ancaman. Hasil penelitian ditemukan beberapa faktor dari unsur analisis SWOT, sebagai dasar untuk melakukan analisis kuantitatif, yang menghasilkan strategi agresif yang harus dikembangkan. Berdasarkan strategi tersebut diformulasikan dalam bentuk bisnis model canvas. Bisnis distro perlu dikembangkan lebih agresif dari sisi Costumer Segment, value proposition, channels, dan costumer relationship agar pendapatan perusahaan dapat meningkat. Perusahaan juga perlu mempertegas pengembangan dari aspek aktivitas bisnis utama, partner kunci dan efektifitas pemanfaatan sumber daya utama agar perusahaan dapat melakukan efisiensi biaya. Temuan dari penelitian ini adalah bahwa BMC dapat digunakan untuk mendeskripsikan secara ringkas tetapi lengkap sebagai upaya untuk memformulasikan strategi hasil analisis SWOT.
\end{abstract}

Kata Kunci: Formulasi strategi, Analisis SWOT dan Bisnis Model Canvas.

\begin{abstract}
The fashion industry plays an important role in the growth of the national creative industry which absorbs a lot of employment. Business actors selected as samples of this study were 4 distribution stores (Distros), located on Jl Padjajaran, Bandung. Increasingly fierce competition is a major problem, marked by declining income and profitability. The purpose of this research is to formulate a distribution business strategy using SWOT analysis and BMC. Qualitative and quantitative descriptive research approaches were used in this study. Qualitative research to identify the factors of strengths, weaknesses, opportunities and threats. The results of the study found several factors from the elements of the SWOT analysis, as a basis for conducting quantitative analysis, which resulted in an aggressive strategy that had to be developed. Based on this strategy it is formulated in the form of a business model canvas. The distros business needs to be developed more aggressively in terms of Customer Segment, value proposition, channels, and customer relationships so that company revenue can increase. Companies also need to emphasize the development of the aspects of key business activities, key partners and the effectiveness of utilizing key resources so that the company can carry out cost efficiency. The finding of this study is that BMC can be used to describe briefly but completely as an effort to formulate a strategy for the results of SWOT analysis.
\end{abstract}

Keyword: Strategic Formulation, SWOT Analysis dan Business Canvas Model

\section{PENDAHULUAN}

Indonesia sebagai negara sedang berkembang dengan penduduk terbesar ke 4 di dunia, dengan tingkat kemiskinan dan pengangguran yang masih tinggi. Kekayaan budaya yang beragam seharusnya menjadi potensi pengembangan sektor ekonomi khususnya industri kreatif. Kesiapan pelaku industri kreatif menjadi faktor kunci dalam menghadapi persaingan (Nugroho, 2019). 
Badan Ekonomi Kreatif telah menetapkan 16 subsektor industri kreatif yang dijelaskan pada Tabel 1. Data Statistik Ekonomi Kreatif Indonesia tahun 2017 menyebutkan bahwa sejak 2010-2015, PDB ekonomi kreatif mengalami kenaikan rata-rata $10,14 \%$ per tahun, dari Rp 525,96 triliun meningkat menjadi Rp 852,24 triliun (Bekraf, 2017).

Tabel 1. Subsektor Industri Kreatif dan Kontribusi PDB

\begin{tabular}{clr}
\hline No & \multicolumn{1}{c}{ Subsektor } & $\begin{array}{c}\text { Kontribusi } \\
\text { PDB }\end{array}$ \\
\hline 1. & Kuliner & $41,69 \%$ \\
2. & Fashion & $18,15 \%$ \\
3. & Kriya & $15,70 \%$ \\
4. & Televisi dan Radio & $7,78 \%$ \\
5. & Penerbitan & $6,29 \%$ \\
6. & Arsitektur & $2,30 \%$ \\
7. & Aplikasi \& Game Developer & $1,77 \%$ \\
8. & Periklanan & $0,80 \%$ \\
9. & Musik & $0,47 \%$ \\
10. & Fotografi & $0,45 \%$ \\
11. & Seni Pertunjukkan & $0,26 \%$ \\
12. & Desain Produk & $0,24 \%$ \\
13. & Seni Rupa & $0,22 \%$ \\
14. & Desain Interior & $0,16 \%$ \\
15. & Film & $0,16 \%$ \\
16. & Desain Komunikasi Visual & $0,06 \%$ \\
\hline Sumber: & Badan Pusat Statistik, 2017 &
\end{tabular}

Salah satu industri kreatif yang berkembang khususnya di Bandung adalah industri fashion, yang diharapkan dapat mendorong tingkat penyerapan tenaga kerja. Sebagai kota tujuan wisata baik domestik maupun manca negara, Bandung menghasilkan produk kreatif seperti T-shirt, sepatu, celana jeans dan pakaian rajut untuk pasar lokal dan internasional. Lebih menggembirakan kreatifitas ini dilakukan oleh generasi muda melalui Distro, Factory Outlet (FO) dan Butik.

Industri ini selain dapat menampung banyak tenaga kerja juga sebagai sarana untuk mengembangkan kreatifitas melalui ide-ide terbaru, mendorong berkembangnya wirausaha baru, meningkatkan citra Kota Bandung sebagai kiblatnya fashion di Indonesia. Bandung sebagai tempat tujuan wisata selain sebagai Kota kuliner juga sebagai pusatnya industri fashion dengan model-model terbaru.

Komitmen bisnis distro ditandai dengan kekhususan produk, kualitas dan harga yang relatif murah. Dengan memperhatikan kecenderungan keinginan konsumen yang berasal dari berbagai kelas ekonomi.

Permasalahan yang dihadapi bisnis distro adalah semakin tingginya persaingan dengan sesama distro, FO dan Butik. Kondisi ini ditandai dengan semakin menurunnya penjualan dan profit yang diperoleh.
Pemecahan permasalahan diatas perlu diawali dengan melakukan reformulasi strategi, didasarkan pada faktor internal: kekuatan (strength), dan kelemahan (weakness) dan faktor eksternal, berupa kesempatan (opportunity) dan ancaman (threat) yang dihadapi.

Analisis SWOT dapat digunakan untuk mengidentifikasi faktor-faktor internal dan eksternal dari bisnis ini. Dengan demikian dapat diidentifikasi dan diukur indikator kelemahan dan kekuatan sebagai faktor internal dan indikator kesempatan dan ancaman sebagai faktor eksternal. Analisis SWOT didasarkan pada asumsi bahwa strategi yang efektif harus dilakukan dengan memaksimalkan kekuatan dan kesempatan, dan meminimalkan kelemahan dan ancaman. Asumsi sederhana ini mengarahkan pada pemilihan dan formulasi strategi yang efektif.

Metode ini, digunakan oleh sebagian besar lembaga baik bisnis dengan orientasi profit maupun nonprofit. Dalam memformulasikan strategi, diawali dengan mengidentifikasi faktor internal dan eksternal yang mempengaruhi lingkungan bisnis sehingga dapat mencerminkan strategi yang diformulasikan sesuai dengan situasi saat ini (Shafieyan \& Homayounfar, 2017).

Analisis SWOT adalah proses penentuan indikator kekuatan, kelemahan, kesempatan dan ancaman yang dihadapi organisasi dan dunia bisnis, (Wisnubroto \& Freitas, 2013). Sedangkan Jogiyanto dalam Widharta \& Sugiharti, (2013) menjelaskan bahwa analisis SWOT digunakan oleh semua organisasi dengan menganalisis kondisi internal (kekuatan dan kelemahan) dalam area fungsional bisnis dan kondisi eksternal yang dihadapi (kesempatan dan ancaman). Tidak ada organisasi atau perusahaan yang sama kondisi internal dan eksternalnya. Kekuatan dan kelemahan internal, digabungkan dengan peluang dan ancaman dari kondisi eksternal dan memperhatikan pernyataan visi, misi menjadi dasar untuk memformulasikan strategi.

Hasil penelitian yang dilakukan oleh (Nwachukwu \& Chladkova, 2017) menunjukkan bahwa perumusan strategi merupakan proses yang memiliki efek positif pada inovasi proses kinerja, kinerja inovasi produk dan pemasaran, dari penelitian tersebut menjelaskan bahwa proses perumusan strategi yang sistematis diperlukan bagi perusahaan untuk mencapai dan mempertahankan kinerja inovasi proses, kinerja inovasi produk dan inovasi pemasaran.

Tujuan dari penelitian ini untuk memformulasikan strategi dengan memanfaatkan kekuatan untuk mengatasi kelemahan (Widharta \& Sugiharti, 2013). Alat yang dipakai untuk menyusun faktorfaktor strategis adalah analisis SWOT dalam bentuk 
matrik. Matrik ini dapat menggambarkan secara jelas mengenai peluang dan ancaman eksternal yang dihadapi, disesuaikan dengan kekuatan dan kelemahan yang dimilikinya. Menurut (Rangkuti, 2015) matrik ini dapat menghasilkan 4 kombinasi alternatif formulasi strategis. Seperti Tabel 2 di bawah ini:

Tabel 2. Matrik SWOT

\begin{tabular}{|c|c|c|}
\hline $\begin{array}{l}\text { IFAS } \\
\text { EFAS }\end{array}$ & Kekuatan (S) & Kelemahan (W) \\
\hline Kesempatan (O) & $\begin{array}{l}\text { STRATEGI } \\
\text { SO } \\
\text { Ciptakan } \\
\text { strategi yang } \\
\text { menggunakan } \\
\text { kekuatan } \\
\text { untuk } \\
\text { memanfaatkan } \\
\text { peluang }\end{array}$ & $\begin{array}{l}\text { STRATEGI } \\
\text { WO } \\
\text { Ciptakan strategi } \\
\text { yang } \\
\text { meminimalkan } \\
\text { kelemahan untuk } \\
\text { memanfaatkan } \\
\text { peluang }\end{array}$ \\
\hline Ancaman (T) & $\begin{array}{l}\text { STRATEGI } \\
\text { ST } \\
\text { Ciptakan } \\
\text { strategi yang } \\
\text { menggunakan } \\
\text { kekuatan } \\
\text { untuk } \\
\text { menghindari } \\
\text { ancaman }\end{array}$ & $\begin{array}{l}\text { STRATEGI } \\
\text { WT } \\
\text { Ciptakan strategi } \\
\text { yang } \\
\text { meminimalkan } \\
\text { kelemahan dan } \\
\text { menghindari } \\
\text { ancaman }\end{array}$ \\
\hline
\end{tabular}

Sumber: (Rangkuti, 2015)

Analisis SWOT dimanfaatkan untuk menentukan alternatif formulasi strategi, dengan mengkombinasikan unsur SWOT, menjadi:

Kuadran 1: kondisi perusahaan secara internal memiliki kekuatan dan memiliki kesempatan yang dapat dimanfaatkan, maka perusahaan dapat memilih strategi agresif.

Kuadran 2: kondisi perusahaan secara internal memiliki kekuatan, tetapi secara eksternal banyak menghadapi ancaman, maka strategi yang dipilih adalah strategi diversifikasi.

Kuadran 3: kondisi internal perusahaan lemah dan banyak ancaman dari sisi eksternal, maka strategi yang dipilih adalah defensive.

Kuadran 4: kondisi internal perusahaan memiliki kelemahan namun secara eksternal masih terdapat kesempatan, maka yang dipilih adalah strategi turn around.

Berikut pengelompokkan kuadran 1, 2, 3 dan 4 hasil dari analisis SWOT dapat dijelaskan melalui gambar 1 .

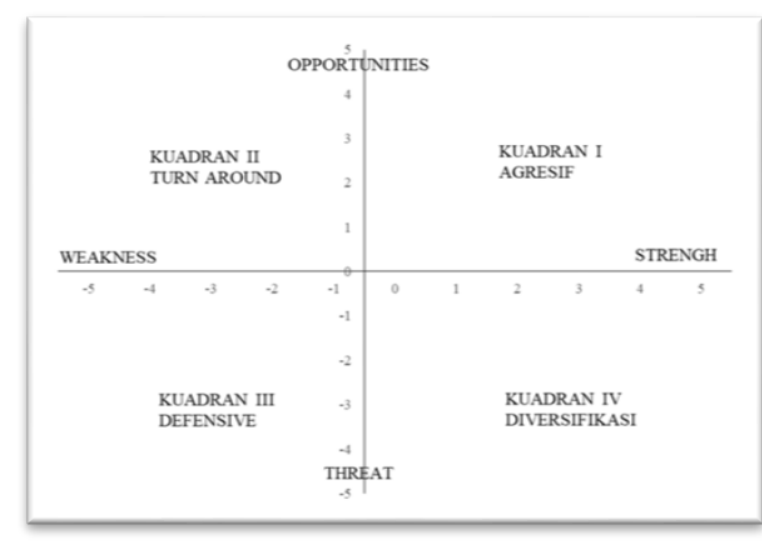

\section{Gambar 1. Kuadran Alternative Strategi}

Langkah selanjutnya dari formulasi strategi hasil dari analisis SWOT, diformulasikan menggunakan BMC, sebagai salah satu alat untuk memformulasikan strategi dengan mendeskripsikan melalui sebuah model bisnis dan menggambarkan dasar pemikiran tentang bisnis untuk menciptakan, memberikan, dan menangkap peluang. BMC merupakan alat untuk membantu memformulasikan strategi yang lebih akurat dari rencana bisnis yang akan dijalani. Mengubah konsep bisnis yang rumit menjadi sederhana yang ditampilkan pada satu lembar kanvas, berisi rencana bisnis dengan sembilan elemen kunci yang terintegrasi dengan baik, di dalamnya mencakup analisis strategi secara internal maupun eksternal (Osterwalder \& Pigneur, 2010). Model BMC dijelaskan pada Gambar 2, berikut:

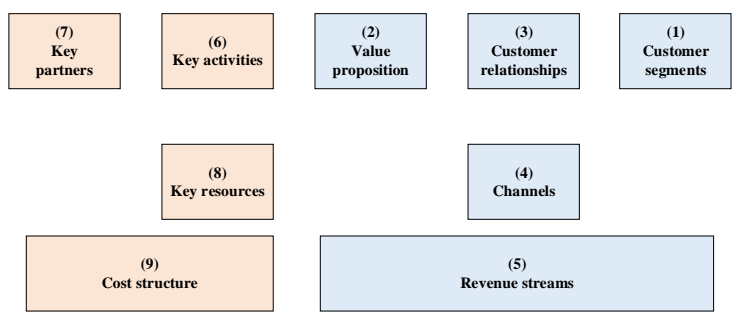

Sumber: (Osterwalder \& Pigneur, 2010), 2017, dimodifikasi.

\section{Gambar 2. Business Model Canvas}

(Christanti et al., 2017), BMC sebagai strategi bersaing bagi pelaku bisnis, dapat digunakan untuk menyusun perencanaan bisnis. Penerapan BMC untuk menciptakan alternatif strategi bisnis di dalam pengembangan kegiatan UMKM (Dwi Prasetyo, 2016).

Menurut (Joyce \& Paquin, 2016) terdapat tiga tingkatan BMC, bahwa BMC sebagai alat untuk mengakselerasi inovasi model bisnis yang berorientasi keberlanjutan. Pertama memperluas BMC dengan menambahkan dua lapisan: lapisan lingkungan berdasarkan perspektif siklus hidup dan lapisan sosial berdasarkan perspektif pemangku kepentingan. Ketika digabungkan, tiga lapisan model bisnis membuat lebih eksplisit sebagai 
sebuah organisasi untuk menghasilkan berbagai jenis nilai ekonomi, lingkungan dan sosial. Mewakili model bisnis secara visual melalui alat kanvas ini mendukung pengembangan dan komunikasi tampilan model bisnis yang lebih holistik dan terintegrasi; yang juga mendukung inovasi kreatif menuju model bisnis yang lebih berkelanjutan. (Hora et al., 2016), mendesain model bisnis berdasarkan hasil penelitiannya, dengan mendesain model bisnis untuk menjaga keberlangsungan bisnis yang dapat digunakan secara umum, sebagai kerangka proposal. Hasil penelitian ini mengintegrasikan berbagai bidang baru untuk keberlanjutan bisnis dalam model bisnis seperti BMC.

Studi ini difokuskan pada bisnis fashion yang disebut bisnis Distro, yang berlokasi di Jl. Padjajaran Bandung.

\section{METODE PENELITIAN}

Penelitian ini menggunakan kombinasi penelitian deskriptif kualitatif dan kuantitatif. Penelitian kualitatif untuk mengidentifikasi berbagai faktor dari unsur SWOT (kekuatan, kelemahan, kesempatan dan ancaman) perusahaan yang dihimpun melalui wawancara langsung kepada narasumber. Penelitian kuantitatif dilakukan untuk memperoleh bobot dan rating dari setiap indikator kekuatan, kelemahan, kesempatan dan ancaman. Instrumen yang digunakan berupa kuesioner dengan jawaban tertutup. Bobot dan rating digunakan untuk menghitung skor sebagai dasar untuk menentukan kuadran strategi, yang didiskripsikan melalui BMC.

Responden dari penelitian ini adalah individu yaitu manajer dan karyawan yang dapat memberikan informasi tentang situasi dan kondisi bisnis dari 4 sampel bisnis Distro. Data yang dikumpulkan berupa data primer yang diperoleh dari responden langsung. Selain itu juga diperlukan data sekunder, yaitu berupa dokumen-dokumen, jurnal atau literatur-literatur lainnya dan data dari Badan Pusat Statistik (BPS) dan internet. Teknik analisis deskriptif yang digunakan dalam penelitian ini.

\section{HASIL DAN PEMBAHASAN}

Berdasarkan tahapan dalam penelitian ini, langkah pertama adalah untuk mengidentifikasi faktor (indikator) kekuatan, kelemahan, kesempatan dan ancaman. Faktor-faktor yang dapat diidentifikasi dari hasil wawancara langsung kepada narasumber seperti disajikan dalam Tabel 3 dan Tabel 4.
Tabel 3: Faktor-faktor Kekuatan dan Kelemahan

Kekuatan

pembaharuan Desain produk dengan edisi terbatas

Bahan baku berkualitas

Lokasi strategis

Pengiriman baang rutin

pengendalian kualitas ketat

Pelayanan toko ramah

Terjalinnya hubungan yang baik dengan supplier

Kelemahan

Endorser and paid promote kurang

Penggunaan website kurang familiar

Lingkup komunitas kurang terjalin

Kemampuan manajerial dalam mengelola usaha

barang dari suplier terbatas

Sumber: Ringkasan hasil wawancara

Tabel 4: Faktor-faktor Kesempatan dan Ancaman

Kesempatan
Dunia fashion cepat berubah
Kedekatan dengan Supplier
Pemanfaatan perkembangan teknologi informasi
Aktif pameran/bazzar pada komunitas anak muda
Ancaman
persaingan tinggi
Nama Distro kurang dikenal
Pesaing baru
Harga murah pada produk tirua
Ada kelompok masyarakat tertentu memilih produk impor

Sumber: Ringkasan hasil wawancara

Faktor-faktor di atas sebagai dasar menyusun kuesioner untuk menentukan bobot dan rating, perkalian keduanya untuk menentukan skor dari setiap faktor. Penjumlahan skor dari setiap faktor pada aspek analisis SWOT. Dengan demikian dapat ditentukan nilai sumbu $\mathrm{X}$ dengan mengurangkan jumlah skor kekuatan dengan jumlah skore kelemahan dan nilai sumbu $\mathrm{Y}$ dengan mengurangkan jumlah skor kesempatan dengan jumlah skor ancaman. Hasil jawaban responden berkaitan dengan bobot dan rating, serta nilai skornya disajikan pada Tabel 5 dan Tabel 6.

Tabel 5: Penilaian Bobot, Rating dan Skor dari setiap Faktor Kekuatan dan Kelemahan

\begin{tabular}{clccc}
\hline Kode & \multicolumn{1}{c}{ Kekuatan } & Weight & Rating & Score \\
\hline S1 & Pembaharuan Desain produk dengan edisi terbatas & 0,16 & 5 & 0,40 \\
S2 & Bahan baku berkualitas & 0,16 & 4 & 0,32 \\
S3 & Lokasi strategis & 0,12 & 5 & 0,30 \\
S4 & Pengiriman barang rutin & 0,12 & 4 & 0,24 \\
S5 & Pengendalian kualitas ketat & 0,16 & 5 & 0,40 \\
S6 & Pelayanan took ramah & 0,14 & 4 & 0,28 \\
S7 & Terjalinnya hubungan yang baik dengan supplier & 0,14 & 5 & 0,35 \\
& Jumlah Score & 1 & & 2,29 \\
\hline Kode & $\quad$ Kekuatan & Weight & Rating & Score \\
\hline W1 & Endorser and paid promote kurang & 0,20 & 2 & 0,20 \\
W2 & Penggunaan website kurang familiar & 0,24 & 1 & 0,12 \\
W3 & Lingkup komunitas kurang terjalin & 0,18 & 2 & 0,18 \\
W4 & Kemampuan manajerial dalam mengelola usaha & 0,22 & 1 & 0,11 \\
W5 & Barang dari supplier terbatas & 0,16 & 2 & 0,16 \\
& Jumlah Score & 1 & & 0,77 \\
& Strengths-Weakness & & & 1,52 \\
\hline
\end{tabular}

Sumber: Hasil Penelitian, Diolah 
Berdasarkan hasil penilaian bobot, rating dan skor dari setiap faktor kekuatan dan kelemahan, kemudian dihitung selisih antara jumlah skor faktor kekuatan sebesar 2,29, dikurangi dengan jumlah skor faktor kelemahan 0,77 , akan menentukan nilai sumbu X sebesar 1,52.

Tabel 6. Penilaian Bobot, Rating dan Skor dari setiap Faktor Kesempatan dan Ancaman

\begin{tabular}{clccc}
\hline Kode & \multicolumn{1}{c}{ Kekuatan } & Weight & Rating & Score \\
\hline 01 & Dunia fashion cepat berubah & 0,16 & 5 & 0,40 \\
02 & Kedekatan dengan supplier & 0,16 & 4 & 0,32 \\
03 & Pemanfaatan perkembangan teknologi informasi & 0,12 & 5 & 0,30 \\
04 & Aktif pameran bazzar pada komunitas anak muda & 0,12 & 4 & 0,24 \\
& Jumlah Score & 1 & & 2,29 \\
\hline Kode & Kekuatan & Weight & Rating & Score \\
\hline T1 & Persaingan tinggi & 0,20 & 2 & 0,20 \\
T2 & Nama distro kurang dikenal & 0,24 & 1 & 0,12 \\
T3 & Pesaing baru & 0,18 & 2 & 0,18 \\
T4 & Harga murah pada produk tiruan & 0,22 & 1 & 0,11 \\
T5 & Adakelompok masyarakat tententu memilih produk impor & 0,16 & 2 & 0,16 \\
& Jumlah Score & 1 & & 0,77 \\
& Opportunities-Threats & & & 1,52 \\
\hline
\end{tabular}

Sumber: Hasil Penelitian, Diolah

Berdasarkan hasil penilaian bobot, rating dan skor dari setiap faktor kesempatan dan ancaman, kemudian dihitung selisih antara jumlah skor faktor kesempatan sebesar 2,01, dikurangi dengan jumlah skor faktor ancaman sebesar 0,59, akan menentukan nilai sumbu Y sebesar 1,22.

Berdasarkan nilai sumbu $\mathrm{X}$ dan $\mathrm{Y}(1,52 ; 1,22)$ dapat ditentukan kuadran alternatif strategi yang dapat dipilih dijelaskan dalam gambar 3 berikut:

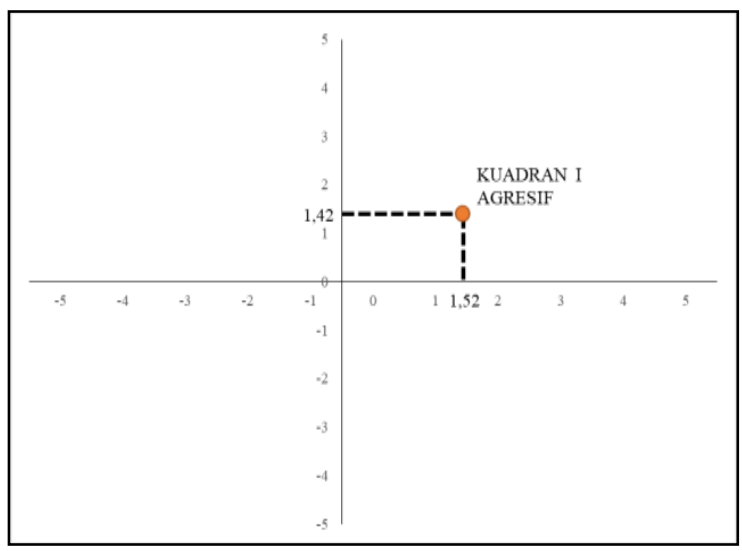

Gambar 3. Alternatif Penentuan Kuadran Strategi

Berdasarkan hasil analisis yang disajikan dalam Gambar 3, alternatif strategi bisnis distro berada di kuadran 1, atau strategi agresif. Kuadran 1 sebagai strategi kekuatan dan kesempatan (StrengthOpportunity) merupakan situasi yang sangat menguntungkan. Bisnis distro memiliki kekuatan secara internal dan tersedia peluang dari faktor eksternal, sehingga dapat dimanfaatkan sebagai peluang untuk mengembangkan usaha secara agresif. Strategi agresif mendukung bisnis distro untuk terus memaksimalkan kekuatan serta peluang yang ada untuk terus maju dan meraih kesuksesan.

Strategi agresif sebaiknya diterapkan pada bisnis distro. Dengan memformulasikan kembali dari aspek costumer segments, Value proportion, channels dan costumer relationships agar dapat meningkatkan revenue streams. Kondisi ini juga harus diimbangi dengan memformulasikan Key partners, key activities, dan key resources, ketiganya memerlukan investasi dan biaya operasional tambahan, kondisi ini akan tetap baik selama tambahan revenue streams masih lebih besar dibandingkan dengan tambahan biaya. Formulasi ini dapat disajikan dalam Gambar 4, yang menggambarkan formulasi strategi bisnis distro kondisi saat ini dengan pendekatan BMC. (lihat Gambar 4). Sedangkan formulasi strategi agresif dari hasil penelitian ini dapat dijelaskan pada Gambar 5. Sehingga dapat dilihat dengan jelas perubahan strategi yang harus dilakukan.

\begin{tabular}{|c|c|c|c|c|}
\hline $\begin{array}{c}\text { Key } \\
\text { partners }\end{array}$ & $\begin{array}{c}\text { Key } \\
\text { activities }\end{array}$ & $\begin{array}{c}\text { Value } \\
\text { proposition }\end{array}$ & \begin{tabular}{|c|}
$\begin{array}{c}\text { Customer } \\
\text { relationships }\end{array}$ \\
\end{tabular} & $\begin{array}{l}\text { Customer } \\
\text { segments }\end{array}$ \\
\hline \multirow[t]{3}{*}{$\begin{array}{l}\text { 8. Suplier atau } \\
\text { Vendor, designer, } \\
\text { Photographer, } \\
\text { Pemiliki }\end{array}$} & $\begin{array}{l}\text { 7. Pelayanan dalam } \\
\text { toko yang ramah } \\
\text { dans sopan temadadap } \\
\text { konsumen }\end{array}$ & \multirow[t]{3}{*}{$\begin{array}{l}\text { 2. Produk yang } \\
\text { ditawarkan selalu } \\
\text { dengan desain } \\
\text { lerbara, secara rutin } \\
\text { disediakan produk } \\
\text { baru, dengan edisi } \\
\text { terbatas, kualias } \\
\text { barang terbaik. }\end{array}$} & $\begin{array}{l}\text { 4. Pelayanan sopan } \\
\text { dan ramah, selalu } \\
\text { tanggap terhadap } \\
\text { keluhan konsumen, } \\
\text { memberikan } \\
\text { informasi mengenai } \\
\text { produk }\end{array}$ & \multirow[t]{3}{*}{$\begin{array}{l}\text { 1. Kelompok anak } \\
\text { muda, mulai dari } \\
\text { pelajar, mahasiswa, } \\
\text { dan karyawan }\end{array}$} \\
\hline & $\begin{array}{c}\text { Key } \\
\text { resources }\end{array}$ & & Channels & \\
\hline & $\begin{array}{l}\text { 6. Karyawan, desain } \\
\text { sederhana, } \\
\text { pengepakan stmadar } \\
\text { perusahaan }\end{array}$ & & $\begin{array}{l}\text { 3.Toko, penjualan on } \\
\text { line (Facebook, } \\
\text { Instagram, dan } \\
\text { Website) }\end{array}$ & \\
\hline \multicolumn{2}{|c|}{ Cost structure } & \multicolumn{2}{|c|}{ Revenue streams } & \\
\hline \multicolumn{2}{|c|}{$\begin{array}{l}\text { 9. Biaya produksi dan biaya non produksi seperti biay } \\
\text { marketing, biaya operasional, dan biaya bahan baku }\end{array}$} & \multicolumn{2}{|c|}{ 5. Hasil penjualan Produk } & \\
\hline
\end{tabular}

Gambar 4. Business Model Canvas Bisnis Distro berjalan

Berdasarkan hasil analisis SWOT diatas diformulasikan strategi agresif untuk bisnis distro, maka bisnis distro ini harus memformulasikan strategi baru dengan menggunakan BMC seperti disajikan pada Gambar 5.

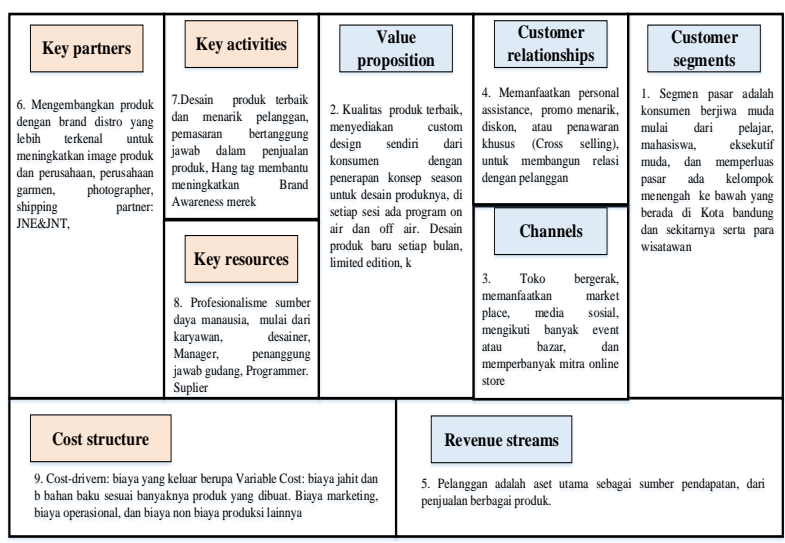

Gambar 5. Rekomendasi Formulasi Strategi Bisnis Distro dengan BMC 
Pembahasan dari penelitian ini adalah diperlukannya perubahan strategi bisnis distro, yaitu dengan strategi bisnis agresif, dengan fokus pada elemen BMC: 1) Costumer segment, fokus pada segmen pelanggan yang meliputi konsumen berjiwa muda mulai dari pelajar, mahasiswa, eksekutif muda, dan memperluas pasar pada kelompok menengah ke bawah yang berada di Kota Bandung dan sekitarnya serta para wisatawan. 2) Value proposition, menjual produk dengan kualitas terbaik, menyediakan custom design sendiri, melayani konsumen dengan penerapan konsep musiman untuk desain produknya, di setiap sesi ada program on air dan off air. Desain produk baru setiap bulan dengan limited edition. 3) Channel, menerapkan model toko bergerak, memanfaatkan market place, media sosial, mengikuti banyak event atau bazar, dan memperbanyak mitra online store. 4) Customer relationship, memanfaatkan personal assistance, promo yang menarik, diskon, atau penawaran khusus (Cross selling), untuk membangun relasi dengan pelanggan. 5) Revenue stream, dengan 4 tindakan di atas, diharapkan dapat meningkatkan penjualan secara berkelanjutan dan berdampak terhadap laba usaha. 6) Key Partners, mengembangkan produk dengan brand distro yang lebih terkenal untuk meningkatkan image produk dan perusahaan, meningkatkan kerja sama dengan perusahaan garmen, photographer, shipping partner: seperti JNE\&JNT, 7) Key activities harus dioptimalkan dengan mendesain produk terbaik dan menarik pelanggan, pemasaran bertanggung jawab dalam penjualan produk, Hand-tag membantu meningkatkan Brand Awareness, 8) Key resources, meningkatkan profesionalisme sumber daya manusia, mulai dari karyawan, designer, Manager, penanggung jawab gudang, Programmer dan Suplier. 9) Cost structure, mengelompokkan biaya menjadi biaya yang benar-benar harus dikeluarkan secara tunai, berupa Variable Cost: biaya jahit dan biaya bahan baku sesuai banyaknya produk yang dibuat. Biaya marketing, biaya operasional, dan biaya non biaya produksi lainnya.

Hasil penelitian ini konsisten dengan penelitian sebelumnya berkaitan dengan perlunya memformulasikan strategi bisnis, untuk menjaga keberlanjutan usaha. Antara lain dengan penelitian yang dilakukan oleh (Nwachukwu \& Chladkova, 2017). Analisis SWOT dapat digunakan untuk memformulasikan strategi bisnis sejalan dengan penelitian (Shafieyan \& Homayounfar, 2017) dan Boseman dalam Wisnubroto \& Freitas, (2013). BMC untuk mendeskripsikan formulasi strategi yang telah ditetapkan. (Christanti et al., 2017), BMC sebagai strategi bersaing bagi pelaku bisnis, dalam menyusun perencanaan bisnis.
Temuan dari penelitian ini adalah bahwa BMC dapat digunakan untuk mendeskripsikan secara ringkas tetapi lengkap sebagai upaya untuk memformulasikan strategi hasil analisis SWOT. Dengan kata lain secara empiris kedua model analisis ini dapat dikombinasikan, yang sifatnya saling mendukung dal melengkapi. Analisis SWOT untuk mengidentifikasi dan menilai kondisi lingkungan internal dan eksternal sebagai dasar untuk menentukan strategi yang diformulasikan dengan menggunakan BMC.

\section{SIMPULAN DAN SARAN}

\section{Simpulan}

Berdasarkan pembahasan di atas sesuai dengan analisis SWOT dapat disimpulkan bahwa bisnis distro perlu dikembangkan dengan strategi agresif. Formulasi strateginya dikembangkan berdasarkan BMC. Untuk meningkatkan pendapatan, bisnis distro harus memformulasikan kembali secara lebih fokus terhadap costumer segments yang didukung dengan penciptaan value proposition, diperkuat costumer relationship dan channels. Struktur biaya harus menjadi perhatian bisnis distro dengan mempertegas key activities bisnis, membangun kepercayaan partner, dan memanfaatkan secara efektif sumberdaya yang dimiliki.

\section{Saran}

Berdasar kesimpulan di atas perlu disampaikan saran, antara lain: bahwa bisnis distro harus selalu mengidentifikasi faktor-faktor dari unsur analisis SWOT untuk mengantisipasi perubahan kondisi lingkungan baik internal maupun eksternal. Bisnis distro untuk tetap menjaga keberlanjutan usaha, perlu mengimplementasi strategi agresif, yang telah diformulasikan dalam peta BMC secara konsisten. Untuk menguji konsistensi hasil penelitian ini dapat dilakukan penelitian ulang dengan pendekatan penelitian kuantitatif menggunakan model statistika yang komprehensif.

\section{DAFTAR PUSTAKA}

Bekraf. (2017). Infografis ringkasan data statistik ekonomi kreatif Indonesia.

Christanti, Y., Umar, A., Sasongko, A. H., \& Widyastuti, I. T. (2017). Business Model Sebagai Strategi Bersaing Untuk Pelaku Bisnis Pemula Studi kasus: Bisnis Hijab. Jurnal Buletin Bisnis \& Manajemen, 03(01), 1-12.

Dwi Prasetyo. (2016). Penerapan Business Model Canvas Untuk Menciptakan Alternatif Strategi Bisnis Di Dalam Pengembangan Kegiatan Usaha Mikro Kecil Dan Menengah Tahun 2015: Vol. 
Hora, M., Hankammer, S., Canetta, L., Sel, S. K., Gomez, S., \& Gahrens, S. (2016). A Framework for the Development of Sustainable Mass Customization Business Models. Proceedings of the 7th International Conference on Mass Customization and Personalization in Central Europe (MCP-CE 2016).

Joyce, A., \& Paquin, R. L. (2016). The triple layered business model canvas: A tool to design more sustainable business models. Journal of Cleaner Production. https://doi.org/10.1016/j.jclepro.2016.06.067

Nugroho, M. T. (2019). Industri kreatif berbasis budaya peluang dan tantangan di era industry 4.0. Jurnal Universitas Muhammadiyah Surakarta, Indonesia, 430-436.

Nwachukwu, C. E., \& Chladkova, H. (2017). Human Resource Management Practices and Employee Satisfaction in Microfinance Banks in Nigeria. Trends Economics and Management.

https://doi.org/10.13164/trends.2017.28.23

Osterwalder, A., \& Pigneur, Y. (2010). Business Model Generation - Canvas. Wiley.

Rangkuti, F. (2015). Riset pemasaran (12th ed.). Gramedia Pustaka Utama.

Shafieyan, M., \& Homayounfar, M. (2017). Identifikasi Strategi untuk Pembangunan Berkelanjutan Produksi Beras di Guilan Provinsi Menggunakan Analisis SWOT Abstrak. International Journal of Management Dan Pengembangan Pertanian, 5852, 141153.

Widharta, W. P., \& Sugiharti, S. (2013). Penyusunan Strategi Dan Sistem Penjualan Dalam Rangka Meningkatkan Penjualan Toko Damai. Manajemen Pemasaran, 2(1), 1-15.

Wisnubroto, P., \& Freitas, J. M. (2013). Strategi Pemasaran Guna Meningkatkan Volume Penjualan Deangan Pendekatan Technology Atlas Project Metod. In Journal Management (Vol. 6, Issue 2, pp. 161-168). 
94 Coopetition, Vol XII, Nomor 1, Maret 2021, 87 - 94

(E-ISSN : 2615-4978, P-ISSN : 2086-4620) 